\title{
INTRODUCTION TO AN INTRODUCTION
}

With lively pleasure I see that you have accepted our invitation to come and give here some elucidations on the subject that you are going to treat in our series of lectures or, if you will, our course on "the analysis of concepts". It may well be called a gratifying phenomenon, that in a time like the present, when we are deluged by a flood of mottos and slogans, a little group of thinking men and women want to meet for the purpose of reflecting on "the concept", which in these days is being handled so heedlessly and which all the same constitutes the nucleus of scientific and philosophic thought - or perhaps I had better say, ought to constitute it.

"Description, not formulae" is a motto rather frequently met with in recent philosophic and scientific literature. People want to take towards the various sciences the attitude which the behaviourist adopts towards all psychical phenomena and processes, but of ten the border-line is drawn too sharply. We are therefore particularly glad that one of our cooperators, Mr. Clay, has given his attention to this subject.

This meeting has had a history leading up to it, if I may call it so. Probably all of you know about the existence of the "International Group for the study of Significs" which lost its international character under the pressure of circumstances. This study-circle, founded in 1937, defined its aim as: the analysis of the basic concepts of science including philosophy and the theory of knowledge, and it is hardly possible, that a similar aim should have been totally foreign to the men who initiated the series of lectures held some six years before the foundation of the I.S.S. These lectures afterwards appeared in print under the title of "De uitdrukkingswijze der wetenschap" ("The means of expression of science"). The critical reader or hearer of that series of lectures will no doubt have been struck by the absence of one single leading principle, accepted by all speakers. Only some of the speakers proved to hold views that were in accordance with the analysis of concepts and with satisfaction I may point out that of these few two are present here.

As the leading principle of our series of lectures and therefore of this meeting too, we have proposed the principle of the critical analysis of concepts. Why? Our answer to this question may be short: it is because from modern critical analysis of concepts we expect a real help in our battle against false notions and pseudo-wisdom.

In the present company there will be no need for me to dilate upon the great strides which the analysis of concepts has made especially in the last few decades. A deepening of logic, not of academic logic with its fixed system of syllogisms, which has after all received a heavy blow from Brouwer's intuitionism, but logic reborn and renewed out of the spirit of mathematics and with which the names of Frege and Russell may be said to be indissolubly connected. The ideas hinted at here were not confined to the domain of mathematics, as you will know. From the point of view of the analysis of concepts it was a momentous step 
forward, when modern methods came to be applied to the subtle apparatus to which all scientific and philosophic thought is bound: language. Whoever sees in knowing not merely scrutinising and experiencing, but operating with concepts represented by signs or symbols, will fully realise the interest of an analysis of interrelation-acts for present-day thought.

In this connection a few words may be devoted to the efforts to evolve a general theory of the forms of thinking or as it is also called, a logical grammar. The theory of logic, both of Aristotelian and modern logic, the whole of mathematics, the system of conventions of physics (as Poincaré sees it), all these are regarded by many present-day thinkers as parts of the one universal grammar. Closely connected with this is the question of the possibilities of application of the "physical language", a subject which will occupy us seriously here.

In the region of the so-called "anorganic sciences" (chemistry, astronomy, geology, etc.) few if any difficulties arise with regard to this applicability. The situation changes however as soon as we enter the region of biology. In the circle of the analysts of concepts a tendency has recently manifested itself to loosen the verifiable core of biological statements from the non-verifiable formulations. In this connection the question belonging to the region of the duality of language comes to the fore: do the laws of nature which suffice for describing the "anorganic phenomena" likewise suffice for the description of the "organic phenomena" ? To the biologist this question is of basic importance quite apart from the form which it usually assumes. For a negative answer to it would lead to the conclusion that biology cannot do without "specifically biological laws" which, as the saying is, cannot be reduced to the physical ones. You know that the "Vitalists" do indeed answer this question in the negative. Other biologists are of opinion that the present results of biological research are far from sufficient to decide this question. But the "physicalist", who considers the physical language as the universal scientific language, will say that this is not so much a matter of the reducibility of biological laws to physical ones as of the reducibility of biological concepts to physical concepts. He does not consider such words as "dominants", "entelechism" and the like as belonging to the biological language but to the language of the vitalistic philosophy of nature. In his opinion, they cannot appear in a statement which has meaning and is verifiable. Every sentence of biology may be translated into the physical language, so physicalism has it. Thus the question in vitalism about the relation in which the biological laws stand to the physical laws is to the physicalist not even a subject for consideration. It is to these problems that the theme "biological concepts and physical concepts" alludes.

In the region of psychology too the application of the thesis of physicalism meets with violent opposition. Is it possible to translate all psychological sentences into physical language? And are the "introspective" statements, as far as they are not translatable into physical language, void of meaning? Suchlike questions may - mutatis mutandis - also be put regarding sociology. 
Last but not least a few words about ethics. In this region as well important clarifying studies have appeared the last few decades. In our country the critical observations of the Dutch ethicist De Bussy have drawn the attention of many people occupying themselves seriously with ethical problems, and the publications of a congenial spirit, Mr. Westendorp Boerma, which testify to a parallel aim have greatly contributed to this. The voice of the lonely figure of De Bussy which for years has been as the voice of one crying in the wilderness, appears to be finding a hearing at last. The ethicist of the school of De Bussy and Westendorp Boerma wants to work with concepts which are no empty husks. He wants to fully appreciate the effect of his words. It is however not only in this quarter that a critical attitude is assumed towards traditional forms of thinking and of language. The logical analysts too have rebelled against "normative ethics", and doubt has arisen as to the truth of Pascal's well-known saying: "Toutes les bonnes maximes sont dans le monde, il ne faut que les appliquer." There too attention is given to the relation between "must" and the concept of "duty", between "may" and the concept of "freedom", between "to be willing" and the concepts of "pleasure and discomfort" and to the analytical description of the phenomenal complexes related to ethical terminology. "Analysis of ethical concepts" is a theme that will doubtless have our full attention.

In conclusion, I should like to say a few words on the subject of methodology. I have already touched upon the importance of a logical grammar. I trust, therefore that I may pass over this point in silence here and presume that Mannoury's work in the field of the methodological analysis of concepts, pioneer-work in many respects, is wellknown in our circle. Those who have undergone the clarifying and widening influence of his studies on the analysis of language - and I am aware this influence makes itself felt outside our country too will realise how glad I am that this significist who is one of the founders of the "Dutch school" will speak in these lectures on such themes as "the word and its physical and psychical correlative" and "an analysis of the elements of will".

Thus I have reached the end of my introduction to an introduction. Perhaps I have succeeded in sketching the main points of the principles which bind the members of this group, the common ambition moving them, the aim they strive after. Both the I.S.S. and the Synthese group have always tried to avoid extremism and dogmatism.

By virtue of our geographical position we, here in Holland, are as it were the logical intermediaries between the extreme currents and trends coming to the fore in present-day cultural life. Not a pre-conceived anti-metaphysical point of view, nor metaphysics that are nothing but an idle play of words, no petrifying systems but no methodless thinking either. Both groups have been willing to understand the words of the mathematician Weyl:

Wer freilich in logischen Dingen nur formalisieren, nicht sehen will - und das Formalisieren is ja die Mathematikerkrankheit - wird weder bei Husserl noch bei Fichte auf seine Rechnung kommen." 